\title{
Experimental and Thermal Network Study on the Performance of a Pins Studded Phase Change Material in Electronic Device Cooling*
}

\author{
Tomoyuki HATAKEYAMA**, Masaru ISHIZUKA**, Sadakazu TAKAKUWA**, \\ Shinji NAKAGAWA** and Kanji TAKAGI** \\ ** Dept. of Mechanical Systems Engineering, Toyama Prefectrural University \\ Kurokawa 5180, Imizu, Toyama \\ E-mail: hatake@ pu-toyama.ac.jp \\ *** Automotive Electronic Components Company, Omron Corporation \\ Zenjozaka 6368, Okusa, Komaki, Aichi
}

\begin{abstract}
This paper describes the results of experimental and analytical work on a phase-changematerial(PCM)-based transient cooling module. The module is made of low-cost materials, yet it is designed to achieve a reasonably high level of heat transfer performance. Paraffin is used as PCM, and it fills the space studded with metallic pin fins. We measured transient temperature rises at several spots of the module. Also, the effects of the dimensional parameters of the pin fins on the heat dissipation performance were investigated. The measured temperatures explicitly reflect the thermal absorption effect of PCM. Analytical work is conducted using a thermal network model where equivalent thermal capacitance are attached to the nodes of the network. The model is validated by the experimental observations, and the simulation code is expected to serve as an efficient analytical tool in the design of PCM-based cooling modules.
\end{abstract}

Key words : Phase Change Material, Thermal Design, Thermal Network Method, Temperature Transient

\section{Introduction}

Thermal design of electronic equipment is gaining its importance as the packaging density in electronic equipment rises rapidly. Furthermore, the assumption of steady-state is no longer taken for granted in many usage environments of electronic equipment. Cooling systems often need to respond to temporary bursts of heat generation; for example, such dynamic heat load variations are experienced by servers in electronic exchange stations during the peak hours of communications traffic. The use of phase change materials (PCMs) has a potential as a means to cope with peak heat loads in high density equipment. It has already been the focus of several studies.

Hodes et al. ${ }^{(1)}$ experimentally investigated the use of PCM for transient thermal management of a handset. They concluded that the use of PCM can increase the service life of a handset. They also calculated the rates of natural convection and radiation heat transfer from the handset to the ambient by numerical analysis. Krishnan and Garimella ${ }^{(2)}$ carried out the analysis of transient heat conduction in a rectangular container which included a PCM to deal with pulsed power dissipation. The effects of pulses frequency, location of heat sources and the aspect ratio of the container were explored in their study. Alawadhi and Amon ${ }^{(3)}$ investigated experimentally and numerically the effectiveness of a Thermal Control Unit (TCU) with PCM in its core in cooling portable electronic devices. They confirmed that the TCU keeps the temperature of the portable device almost constant at the melting point of a PCM. Pal and Joshi ${ }^{(4)}$ demonstrated the potential of finite volume method to predict the performance of PCMs in passive cooling applications. The PCMs in their study are n-Eicosene and eutectic

*Received 13 Jan., 2011 (No. 11-0030) [DOI: 10.1299/jtst.6.164]

Copyright $\subset 2011$ by JSME 
alloy of $\mathrm{Bi} / \mathrm{Pb} / \mathrm{Sn} / \mathrm{In}$. Wirtz et al. ${ }^{(5),(6)}$ explored the use of a solid-solid dry PCM for electronics cooling application. They constructed a semi empirical heat transfer model composed of thermal capacitive elements and thermal resistances.

Organic PCMs generally have low thermal conductivity. To enhance effective thermal conductivity of PCMs, several measures have been investigated. Weinstein et al. ${ }^{(7),(8)}$ embedded graphite nanofibers into a paraffin to improve the thermal conductivity of PCM. The graphite fiber type, the fiber loading level, and the PCM container size are varied in their study. Bauer and Wirtz ${ }^{(9)}$ measured the effective thermal conductivity of a PCM in impregnated aluminum form. They reported that an increase in aluminum fraction increases the effective thermal conductivity of PCM due mostly to heat flow through the form. Lafdi et al. ${ }^{(10)}$ performed numerical analysis for the heat sinks which include form structures impregnated with PCMs. The form properties such as porosity, pore size, and thermal conductivity are treated as design parameters.

As for the method of thermal analysis we need a design tool that enables us to optimize the structure of cooling devices. Commercially available Computational Fluid Dynamics (CFD) codes are generally accepted design tools. However, when applied to problems including phase changes, the CFD code is not an efficient tool. Although it allows in-depth analysis of temperature and flow distribution, it consumes long computation time even on a high-end computer.

Ishizuka et al. ${ }^{(11)}$ proposed a thermal management method suitable for in-situ thermal management. In the first phase of their work, CFD simulations were performed to examine the thermal behavior of PCM in detail inside and outside the equipment casings. In the second phase, a model in the form of thermal network was developed on the basis of CFD simulation results. The model thus developed was used to conduct a design parameter survey. Since the thermal network model requires less calculation time than the CFD simulation, its extensive use is expected. Ishizuka ${ }^{(12)}$ reported the thermal network analysis for packages that contain a highly conductive low-melting-point alloy that serves as a PCM. In the study, he used a simple model in which the PCM temperature was fixed at its melting point during the PCM phase change phase. However, it has not yet been clarified whether the thermal network modeling methodology is effective in analyzing the behavior of PCM with low thermal conductivity such as paraffin.

In this study, we conducted an experiment to verify the effectiveness of latent heat of paraffin in dealing with transient heat dissipation from simulated electronic devices. We also proved the usefulness of a thermal network model in the prediction of temperature rises in low-conductive paraffin.

2. Nomenclature
$A:$ Area $\left[\mathrm{m}^{2}\right]$
$c_{p}:$ Specific heat $[\mathrm{J} /(\mathrm{kg} \cdot \mathrm{K})]$
$C$ : Thermal capacitance $[\mathrm{J} / \mathrm{K}]$
$D$ : Experimental constant [-]
$d:$ Fin diameter of heat sink [mm]
$G_{r}:$ Grashof number $=\left(g \rho \beta \Delta T L^{3} / \mu^{2}\right)$
$h:$ fin height $[\mathrm{m}]$
$l$ : Conduction length [m]
$L$ : Reference length [m]
$L_{a}$ : Latent heat of fusion $[\mathrm{J} / \mathrm{kg}]$
$N u$ : Nusselt number $(=\alpha L / \lambda)$
$P$ : Heat dissipation [W]

$$
\begin{aligned}
\operatorname{Pr} & : \text { Prandtl number }\left(=\mu c_{p} / \lambda\right) \\
Q & : \text { Heat flow }[\mathrm{W}] \\
R & : \text { Thermal resistance }[\mathrm{K} / \mathrm{W}] \\
T & : \text { Temperature }\left[{ }^{\circ} \mathrm{C}\right] \\
t & : \text { Time }[\mathrm{s}] \\
V & : \text { Volume of node }\left[\mathrm{m}^{3}\right] \\
\alpha & : \text { Heat transfer coefficient } \\
& {\left[\mathrm{W} /\left(\mathrm{m}^{2} \cdot \mathrm{K}\right)\right] } \\
\epsilon & : \text { Emissivity }[-] \\
\rho & : \text { Density }\left[\mathrm{kg} / \mathrm{m}^{3}\right] \\
\sigma & : \text { Stefan-Boltzmann constant, } 5.67 \times \\
& 10^{-8} \mathrm{~W} /\left(\mathrm{m}^{2} \mathrm{~K}^{4}\right)
\end{aligned}
$$

\section{Experimental Apparatus}

Figure 1 shows a schematic view of the experimental apparatus. It consists of a test module, a DC power unit to supply power to the heat source, a data logger to collect temperature 
data, a thermostatic chamber to maintain stable temperature environment for the test module. The module is suspended in the chamber, so that heat from the module is dissipated in the chamber by natural convection and radiation.

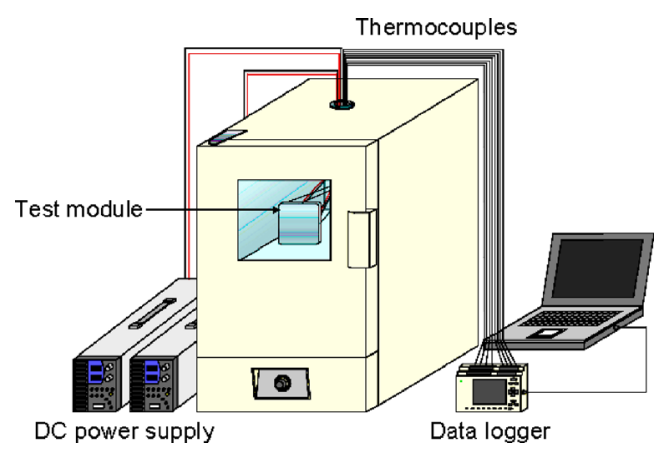

Fig. 1 Experimental apparatus.

The test module is shown in Fig. 2. The module is consisted of a substrate and a heat sink. The footprint area of the module is $85 \mathrm{~mm} \times 85 \mathrm{~mm}$. The substrate is a $2 \mathrm{~mm}$-thick aluminum plate on which two resistors are bonded. Between the substrate and resistors, the heat spreader, which is thin aluminum film, is located for good attachment between them. The resistors serve as simulated chips. The heat sink has an exterior thickness of $14 \mathrm{~mm}$, and the lower side of its aluminum casing is bonded to the upper surface of the substrate. To reduce contact thermal resistance, silicone grease is applied between the substrate and the heat sink. The heat sink has an internal space to accommodate the PCM. The dimensions of the space are about $81 \mathrm{~mm} \times 81 \mathrm{~mm} \times 10 \mathrm{~mm}$. Cylindrical fins are provided inside the heat sink to enhance heat conduction to the PCM.

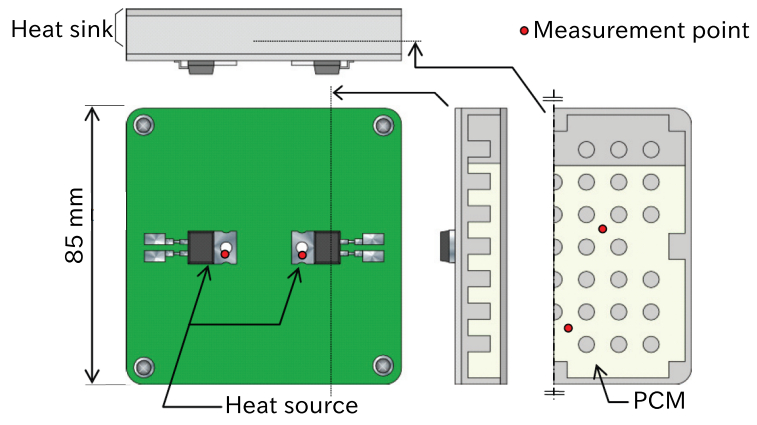

Fig. 2 Test module.

The diameter and the number of pins are varied as shown in Fig. 3: $2.5 \mathrm{~mm}$ fin $\times 180$, $5 \mathrm{~mm}$ fin $\times 45$, and $33.5 \mathrm{~mm}$ fin $\times 1$ (the diameter $\times$ the number of pins). The height of each pin is $7 \mathrm{~mm}$. There is a gap of $3.0 \mathrm{~mm}$ between the pin tips and the casing surface as shown in Fig. 3. These three heat sinks have the same weight, $125 \mathrm{~g}$. This means the volume of the internal space is constant in all cases.

Paraffin (Nippon Seiro's 155) was used as the PCM . The mass of paraffin in the heat sink is $37 \mathrm{~g}$. Table 1 lists the properties of the PCM and aluminum (ADC50). The specific heat and the thermal conductivity in Table 1 are those of commercially available paraffin. We poured melted paraffin into the heat sink. Volume of melted paraffin is $4.7 \times 10^{4} \mathrm{~m}^{3}$. Considering volume of cylindrical fins, $81.4 \%$ of inner space is filled by melted paraffin as shown in Fig. 3. Before starting the experiment, paraffin is cooled down and becomes solid state. However, the space shown in Fig. 3 is filled by paraffin with some voids due to cooling from any surface of the heat sink. 

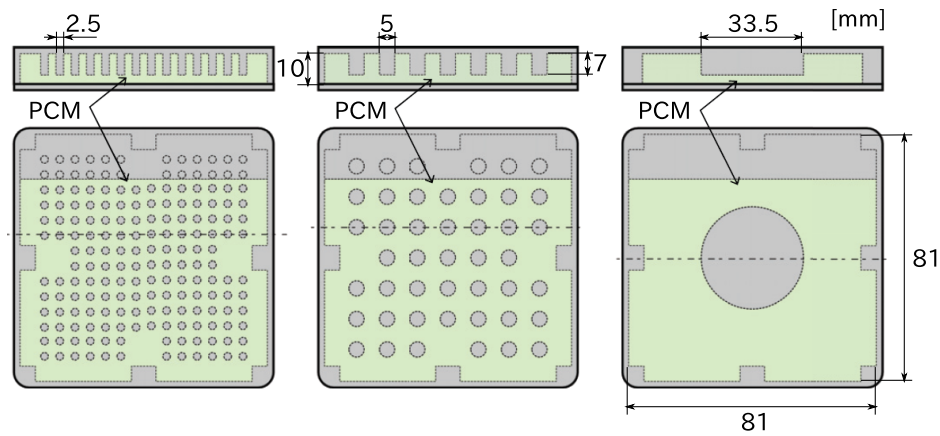

Fig. 3 Layout of pin-fins in the heat sink module.

Table 1 Properties of the PCM and aluminum (ADC50).

\begin{tabular}{cccccc}
\hline & $\begin{array}{c}\rho \\
{\left[\mathrm{kg} / \mathrm{m}^{3}\right]}\end{array}$ & $\begin{array}{c}c_{p} \\
{[\mathrm{~J} / \mathrm{kg} \cdot \mathrm{K}]}\end{array}$ & $\begin{array}{c}\lambda \\
{[\mathrm{W} / \mathrm{m} \cdot \mathrm{K}]}\end{array}$ & $\begin{array}{c}L_{a} \\
{[\mathrm{~kJ} / \mathrm{kg}]}\end{array}$ & $\begin{array}{c}T_{\text {melt }} \\
{[\mathrm{K}]}\end{array}$ \\
\hline Paraffin (solid) & 927 & 1970 & 0.23 & 197 & $313-343$ \\
Paraffin (liquid) & 783 & 2180 & 0.13 & & \\
ADC50 & 2700 & 963 & 96.0 & - & - \\
\hline
\end{tabular}

\section{Experimental Method}

We conducted experiments setting the power input to the resistors $P$ at 15,20 , and 30 $\mathrm{W}$; the power is equally divided between the two resistors. The heat dissipation was varied by adjusting the supply voltage. The temperatures were measured at several spots in the module (see Fig. 2) by means of thermocouples ( $0.1 \mathrm{~mm}$ diameter K-type), and recorded at every second. The experimental run follows the sequence; initially, the test module is at room temperature $(293 \mathrm{~K})$, then, stepwise power is applied to the resistors, and the run is terminated after 4000 or 6000 seconds. The uncertainty in temperature measurement is estimated to be $\pm 1.9 \mathrm{~K}$. In reporting the data in the following section 'the temperature in the PCM' is the average of temperature readings obtained at five locations in the PCM zone. Also, 'the heat source temperature' is the average of temperatures on the two resistors.

\section{Experimental Results}

Figures 4 and 5 show the records of temperatures measured in the PCM and the heat source (resistor), respectively. The parameter is the fin diameters; the data for three diameters $2.5,5$ and $33.5 \mathrm{~mm}$ are shown. The power to the resistors is given impulsively at time zero, and held constant at $30 \mathrm{~W}$. Figure 5 also includes the data of a case where the PCM was removed from the 5mm-pin module. As seen in Figs. 4 and 5, the temperature increases rapidly with time after power input until it reaches the PCM's melting point. During this initial transient period the heat is stored as sensible heat in the substrate, the heat sink, and the PCM. The temperature rise is suppressed in the following 500 to 1000 seconds, during which the PCM temperature reaches around $333 \mathrm{~K}$. This is due to the absorption of heat by phase change of PCM. The phase of the PCM completely changes to liquid at 1200 seconds. During the melting phase the temperature of the heat source with the $33.5 \mathrm{~mm}$-pin heat sink is about $4 \mathrm{~K}$ higher than in the other two cases. (Fig. 5(b)) This difference is caused by a decrease of interface area to the PCM on this large-diameter pin. The heat source temperature histories of all the cases become almost indistinguishable after 1200 seconds.

Figure 5 clearly shows the effectiveness of PCM in suppressing the temperature rise in a long period of time. Suppose a case where the heat source temperature is allowed to rise up to, say, $398 \mathrm{~K}$ (allowable junction temperature of Silicon Carbide (SiC) devices). The heat sink without PCM allows heat dissipation from the heat sources up to 1000 second, whereas that with PCM up to 2000 second.

Thus, the thermal absorption by PCM doubles the operating time of the electronic devices. The heat sink casing weighs $125 \mathrm{~g}$ and the PCM weighs $37 \mathrm{~g}$, so the total weight of 


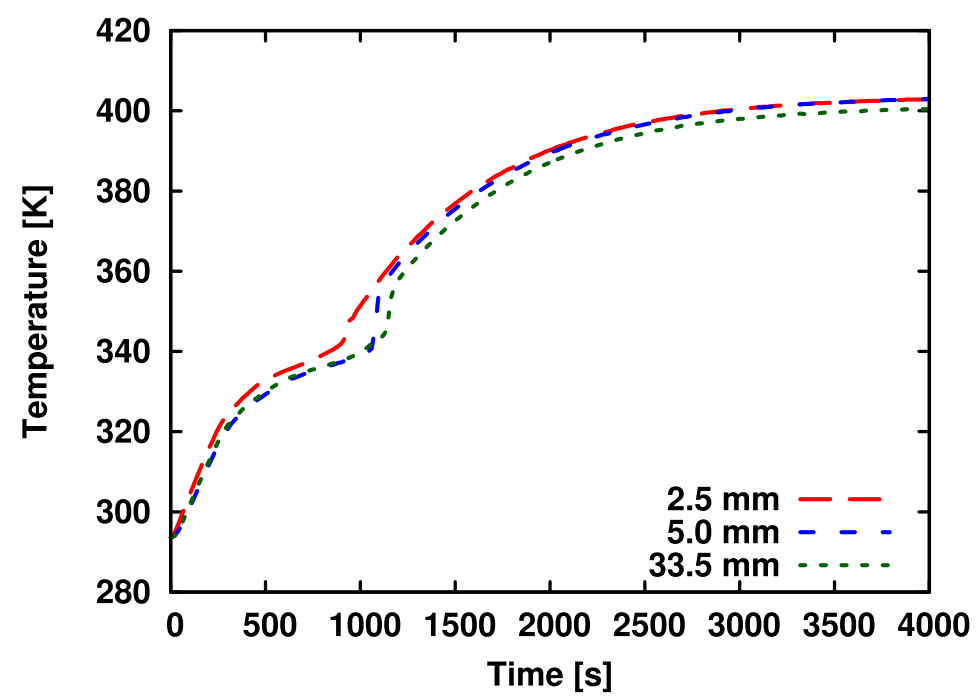

Fig. 4 Temperature transients in the PCM for power input of $30 \mathrm{~W}$. The parameter is the pin diameter.

the PCM-filled module is larger than that of the hollow module by $30 \%$. This added weight, however, is a disguise of a large benefit brought by PCM. To show this, suppose that a PCMfilled module is designed to have the safe operation time of 1000 second. By a rule of thumb we halve the PCM mass to $19 \mathrm{~g}$, and this allows also the weight of the casing be halved to 63 $\mathrm{g}$. The total weight of the new design is $82 \mathrm{~g}$, hence, a significant reduction in the weight and the size of the cooling system would result.

Figures 6 and 7 show the temperature transients measured in the PCM and on the heat source, respectively. The parameter is the power input to the resistors; it is set at three levels, 15, 20, and $30 \mathrm{~W}$. These data belong to the $5 \mathrm{~mm}$-pin module. The curves exhibit the features that agree with our expectations. The larger the power input, the faster the temperature rises. The time for the PCM to reach its melting point decreases with increasing the power input (Fig. 6).

The heat source temperature levels off beyond certain time, and its steady state level lowers with decreasing the power input (Fig. 7). When the maximum permissible temperature is set at, say, $398 \mathrm{~K}$, the curves for 15 and $20 \mathrm{~W}$ do not surpass this limit. This indicates that, for this temperature criterion, the power input lower than $20 \mathrm{~W}$ allows the operation of the electronic device for indefinite period of time.

\section{Thermal Network Model}

Figure 8 shows a thermal network model of the module; the illustration is for the $5 \mathrm{~mm}$ pin module. To conduct transient heat conduction analysis, the thermal network is composed involving the thermal resistance $R$ and the thermal capacitance $C$. The nodes are linked to each other through the thermal resistances that are written in terms of the element dimensions and thermal conductivity. Thermal resistances by natural convection and radiation are written for the link between the boundary surface node and the environment (ambient air). The effect of natural convection in liquid phase of the PCM is neglected in this analysis. For obtaining much faster calculation time than CFD analysis, which is an advantage of thermal network analysis, we introduce simple thermal network model as shown in Fig. 8. In Fig. 8, "R:" represents thermal resistance. We introduced 7 thermal resistances of pins. The procedure for constructing this model will be shown later.

Thermal capacitance $C$ is calculated using the following equation.

$$
C=q V c_{p}
$$




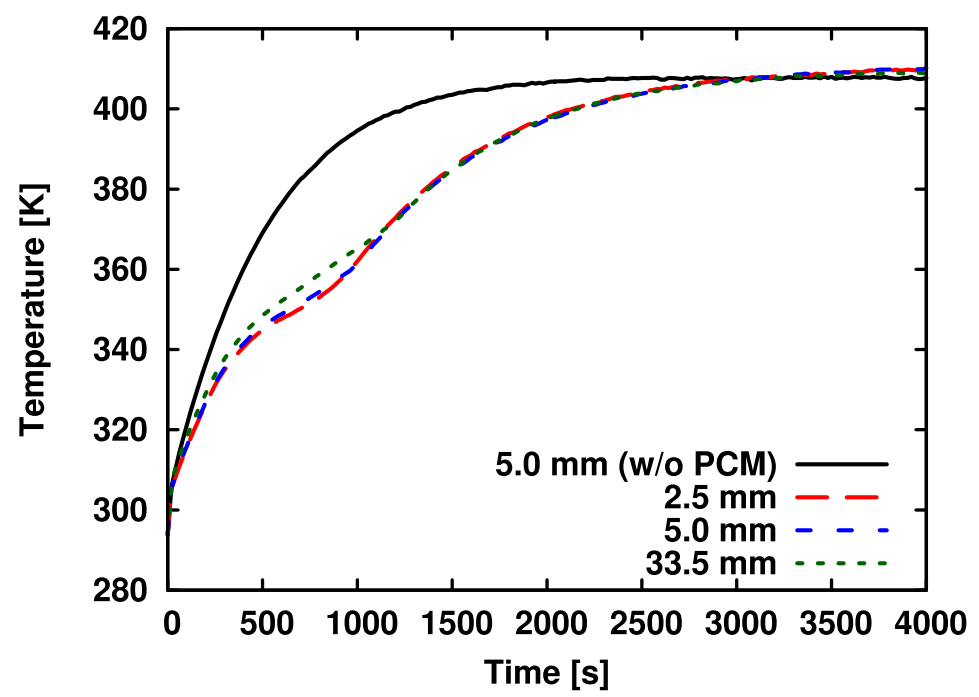

(a) 0 to 4000 second

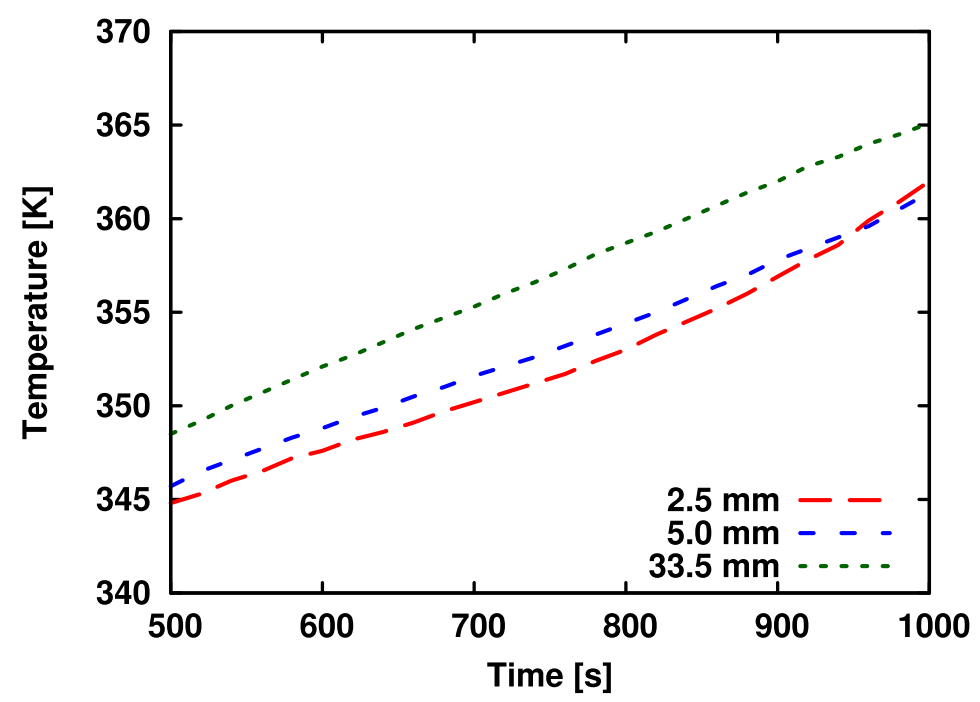

(b) 500 to 1000 second

Fig. 5 Temperature transients in the heat source for power input of $30 \mathrm{~W}$. The parameter is the pin diameter. 


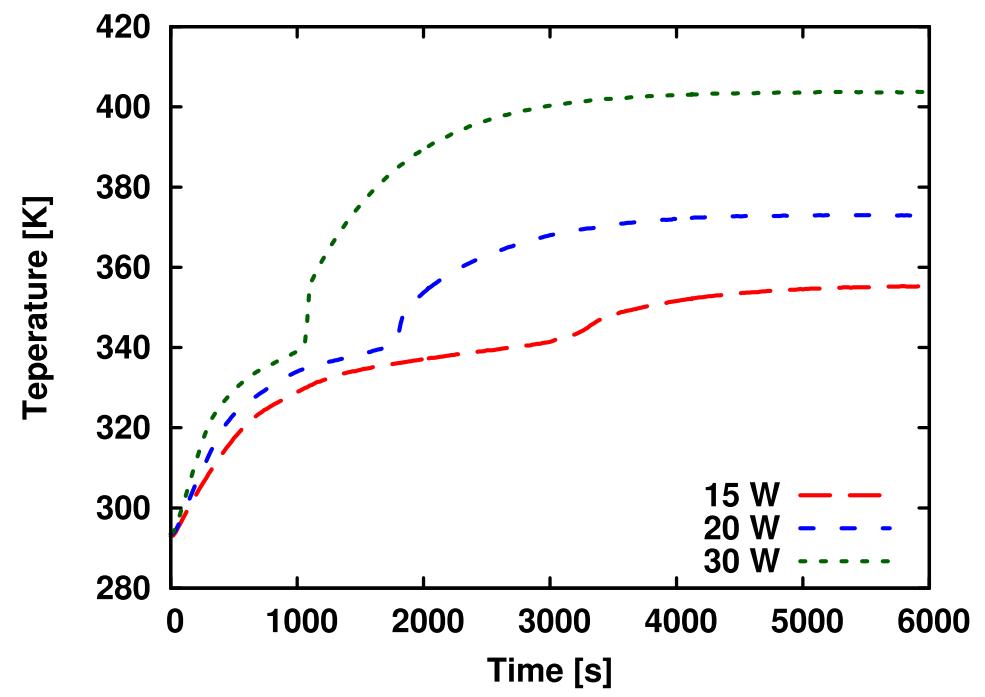

Fig. 6 Temperature transients in the PCM obtained on the 5mm-pin module. The parameter is the power input.

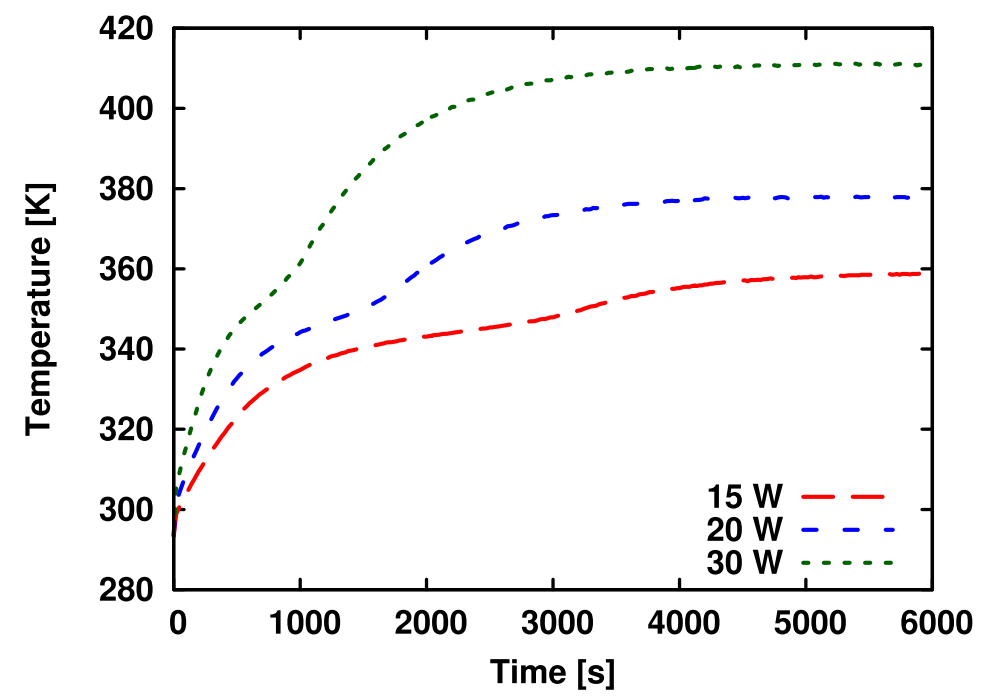

Fig. 7 Temperature transients in heat source obtained on the $5 \mathrm{~mm}$-pin module. The parameter is the power input. 


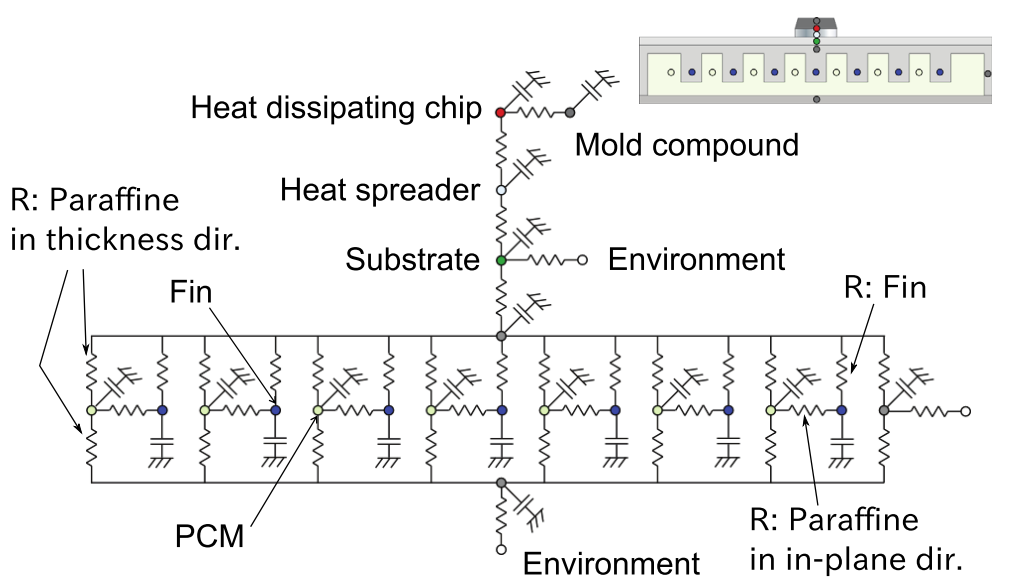

Fig. 8 Thermal network model.

where $\rho$ is the density, $V$ is the volume around the node, and $c_{p}$ is the specific heat. Thermal resistance is written as

$$
R=\frac{l}{\lambda A}
$$

where $l$ is the heat conduction distance, $\lambda$ is the thermal conductivity. The resistance for heat conduction from the node on the cylindrical pin to that in the PCM is calculated by the following equation assuming radial heat conduction from the pin surface to the surrounding PCM.

$$
R=\frac{\ln \left(r_{2} / r_{1}\right)}{2 \pi \lambda h}
$$

where $r_{2}$ and $r_{1}$ are half of the fin pitch and the radius of the pin, respectively. $h$ is the pin height. Thermal resistance by natural convection is calculated using the following equation with heat transfer coefficient $\alpha$.

$$
R=\frac{1}{\alpha A}
$$

The heat transfer coefficient is obtained from the following equation for natural convection on the flat plate.

$$
\alpha=2.8 D\left(\frac{\Delta T}{L}\right)^{0.25}
$$

where $\Delta T$ is the temperature difference between the object and the ambient temperature, $D$ is the experimental constant, and $L$ is the reference length. We set the coefficient $D$ to 0.56 , the value usually adopted for natural convection heat transfer from the vertical plane. The side length of the substrate $(85 \mathrm{~mm})$ is employed as the reference length. Equation (5) is the approximation of Eq. (6) at atmospheric pressure and moderate temperature.

$$
N u=D(G r \cdot P r)^{0.25}
$$

where $N u$ : Nusselt number, $G r$ : Grashof number, $\operatorname{Pr}$ : Prandtl number. Thermal resistance by radiation from the object of temperature $T[\mathrm{~K}]$ to the ambient air of temperature $T_{a}$ $[\mathrm{K}]$ is obtained by the following equation setting the view factor as $F=1.0$.

$$
R=\frac{1}{\epsilon \sigma F A\left(T^{2}+T_{a}^{2}\right)\left(T+T_{a}\right)}
$$

where $\epsilon$ is the emissivity, and $\sigma$ is the Stefan-Boltzmann constant. The thermal resistance for the heat path from the resistor element to the heat spreader on the resistor package is set as $2.3 \mathrm{~K} / \mathrm{W}$ referring to the data supplied by the resistor vendor. 
Since it is difficult to formulate the interface thermal resistance between the resistor package and the substrate, we left the interface resistance value undetermined at the stage of network formulation. It was determined later so as to make the predicted temperatures at the measurement spots agree with the corresponding measured data.

By using the thermal resistance and the thermal capacitance mentioned above, we constructed the thermal network model as follows. In the experiment, paraffin covers about $81.4 \%$ of the inner space of the heat sink. Hence 39 pins touch paraffin in the case of $50 \mathrm{~mm}$ diameter pin, and the space, where paraffin does not exist, is neglected in the thermal network model. Now we consider only half of the heat sink. Therefore, we consider the part shown in Fig. 9. Thermal resistance of one pin can be calculated from Eq. (2). In the model of Fig. 9, the number of pins is 19.5. Hence, total thermal resistance of all pins is thermal resistance of one pin divided by 19.5 because of larger heat diffusion area. In the thermal network model of Fig. 8, we employ 7 thermal resistances for pins. Then one thermal resistance in Fig. 8 becomes total thermal resistance of all pins times 7. Each thermal capacitance of the pins in Fig. 8 can be calculated from total thermal capacitance of the pins in Fig. 9 divided by 7 . Thermal resistance in in-plane direction can be calculated from Eq. (3). Outer diameter is half pitch of the pins and inner diameter is outer radius of pins. This thermal resistance corresponds to heat transfer from pin to paraffin in in-plane direction. Considering the number of the pins in Fig. 9, total thermal resistance of paraffin in in-plane direction becomes thermal resistance around one pin divided by 19.5. Since there are 7 thermal resistances in the thermal network model of Fig. 8, one thermal resistance in Fig. 8 is total thermal resistance times 7. Thermal capacitance of paraffin is determined by total thermal capacitance of paraffin divided by 7 . Two thermal resistances of cooling on the heat sink surface are considered due to higher thermal conductivity and assumption of uniform temperature distribution obtained by thermal network analysis with several nodal points on the surface of the heat sink. Thus thermal network model shown in Fig. 8 was constructed.

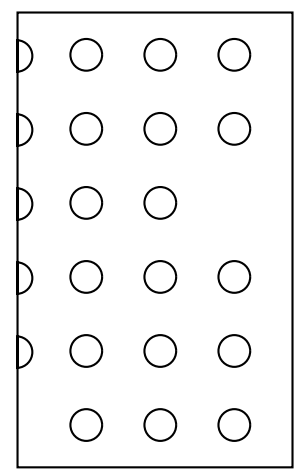

Fig. 9 Schematic image for thermal network model in the case of $5 \mathrm{~mm}$ fins.

Initially, at time zero, the temperatures of all nodes are set at $293 \mathrm{~K}$. Since the model is symmetric with respect to its center vertical plane, only a half of the network suffices for our analysis. Hence, power $P / 2$ [W] is applied to the chip node. Energy balance equations are written for all nodes and solved using the Runge-Kutta method. The solution proceeds in time-marching; from the solution at time $t$, a solution for the next time level $t=t+\Delta t$ is obtained. Then, the thermal resistances $R$ are updated substituting new values of $\Delta T$ in Eqs. (4) and (7).

\section{Modeling of Melting PCM Elements}

The phase change processes in PCM are modeled in terms of equivalent specific heat. The equivalent specific heat is found experimentally as a function of the temperature as shown in Fig. 10. The data of specific heat are obtained using a difference scanning calorimeter (DSC). To incorporate the data in the network analysis, the DSC curve is divided to several 
segments, and each segment is approximated by a linear function.

The specific heat of a PCM volume around the node is calculated as follows. Initially, the element is in solid phase, hence, the specific heat is set as $c_{s}=1.97 \mathrm{~kJ} /(\mathrm{kg} \cdot \mathrm{K})$. After the node temperature exceeds $313 \mathrm{~K}$, the equivalent specific heat is used for calculation. It is calculated by the following equation.

$c_{\text {equ }}=c_{s}+\Delta c$

An increment $\Delta c$ corresponds to heat absorption by melting of PCM and is defined by a piece-wise linear function of the temperature. We employed following equations.

$\Delta c(T)=0.279 \times(T-273)-9.21$

for $313<\mathrm{T} \leq 331$

$\Delta c(T)=1.45 \times(T-273)-77.1$

for $331<\mathrm{T} \leq 341$

$\Delta c(T)=-6.51 \times(T-273)+464$

for $341<\mathrm{T} \leq 344$

After the temperature exceeds $344 \mathrm{~K}$, the specific heat of liquid phase $c_{l}$ is used for calculation. Note that the area under the DSC curve of Fig. 10 is equal to the latent heat of PCM $(197 \mathrm{~kJ} / \mathrm{kg})$. This means as follows.

$$
\int_{313}^{344} \Delta c(T) d T-\int_{313}^{344} 1.97 d T=197
$$

In the calculation, thermal properties of solid phase is applied to the case that paraffin is in solid phase, and thermal properties of liquid phase is applied after paraffin melts as shown in Table 1.

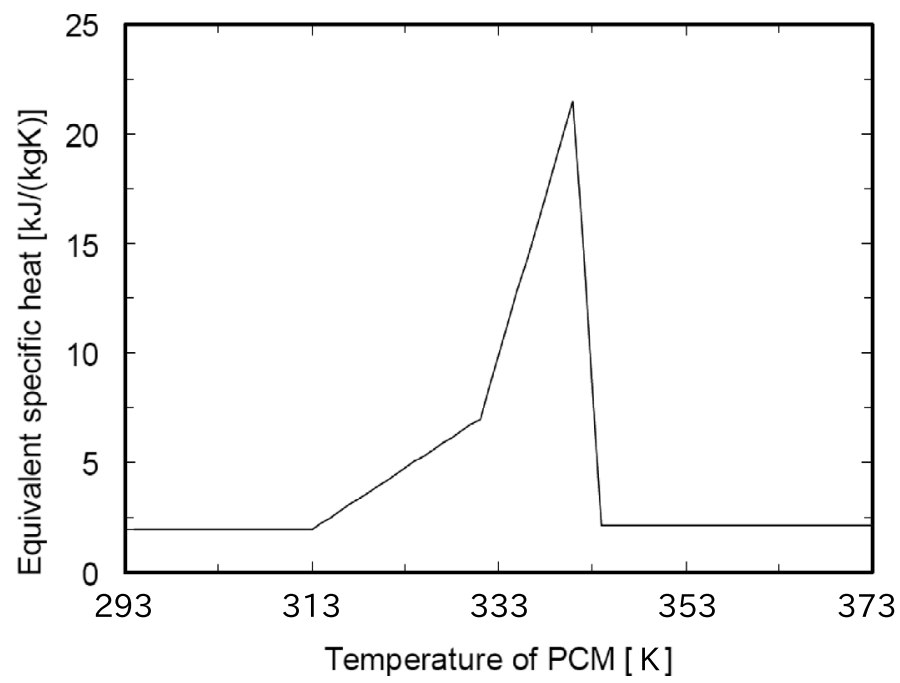

Fig. 10 Equivalent specific heat.

\section{Numerical Results and Discussion}

In Figs. 11 and 12 the results of numerical and experimental work are compared taking the pin diameter as parameter. In the following discussion, PCM temperature from the numerical analysis is average temperature of 7 nodal points in Fig. 8. Figure 11 shows the 
temperature transients in the PCM, and Fig. 12 shows the temperature transients on the heat source. The data in these figures are for the power input of $P=30 \mathrm{~W}$. Maximum discrepancy of PCM temperature in $2.5 \mathrm{~mm}$ case is $6.9 \mathrm{~K}$, and that in $5 \mathrm{~mm}$ case is $5.9 \mathrm{~K}$, that in 33.5 $\mathrm{mm}$ case is $10.4 \mathrm{~K}$. Maximum discrepancy of heat source temperature in $2.5 \mathrm{~mm}$ case is 4.4 $\mathrm{K}$, and that in $5 \mathrm{~mm}$ case is $4.1 \mathrm{~K}$, that in $33.5 \mathrm{~mm}$ case is $5.2 \mathrm{~K}$. In the case of $33.5 \mathrm{~mm}$ case, the discrepancy is large due to simplicity of the thermal network model. However, the numerical results are in good agreement with the experimental results. The numerical analysis accurately reproduces the portions of the curves corresponding to the melting process of PCM, and follows the experimental curves all the way to the steady state. This means that the present analysis serves as a useful and reliable tool for the design of a cooling module using PCM.

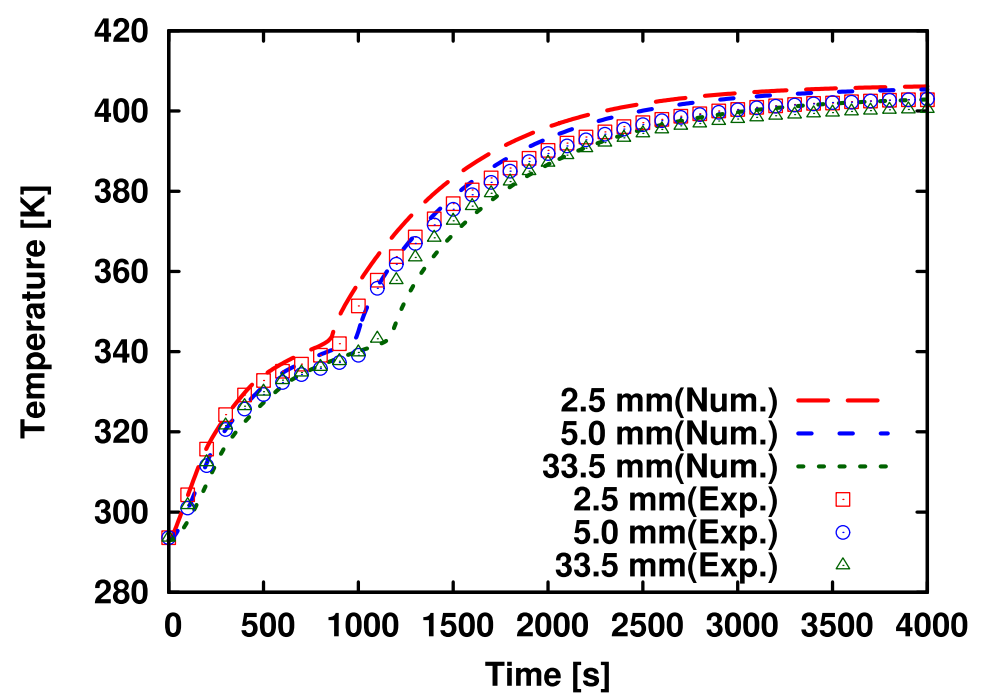

Fig. 11 Comparison of numerical and experimental temperature of the PCM for three pin diameters.

Figures 13 and 14 show a comparison between the experimental and numerical temperatures where the power input is taken as parameter. The data belong to the $5 \mathrm{~mm}$-pin module. Figure 13 shows the temperature transients in the PCM, and Fig. 14 shows those on the heat source. Differences of melting time and steady state temperature of the PCM incurred by varying the power input are accurately captured by the numerical analysis. Maximum discrepancy of PCM temperature in $15 \mathrm{~W}$ case is $7.5 \mathrm{~K}$, and that in $20 \mathrm{~W}$ case is $7.4 \mathrm{~K}$, that in $30 \mathrm{~W}$ case is $5.9 \mathrm{~K}$. Maximum discrepancy of heat source temperature in $15 \mathrm{~W}$ case is $4.1 \mathrm{~K}$, and that in $20 \mathrm{~W}$ is $2.4 \mathrm{~K}$, that in $30 \mathrm{~W}$ case is $4.1 \mathrm{~K}$. The analytical and experimental results agree at all levels of power input. This again proves that the thermal network method is an effective tool for thermal design. It appears possible to formulate the guidelines for the selection of PCM and the design of the module to keep the temperature of the electronic devices within an allowable range.

Furthermore, the present analytical model can be used to predict temperature variations experienced by the electronic device in time of varying load in practical applications. Figure 15 shows the results obtained by varying the power input in a simulated cyclic mode. The power was on at $30 \mathrm{~W}$ for 1000 second, was off for the next 1000 second, again back to $30 \mathrm{~W}$ for 1000 second, then off for 1000 second. This power cycle was repeated until 6000 second in the experiment and the calculation. It can be seen that the maximum heat source temperature was controlled under the limit temperature of $398 \mathrm{~K}$ during all the operation time. When the power supply is stopped, the temperature decreases to the melting point of the PCM and the temperature drop is decelerated due to emission of fusion heat during solidification.

The numerically obtained temperatures are in good agreement with the experimental re- 


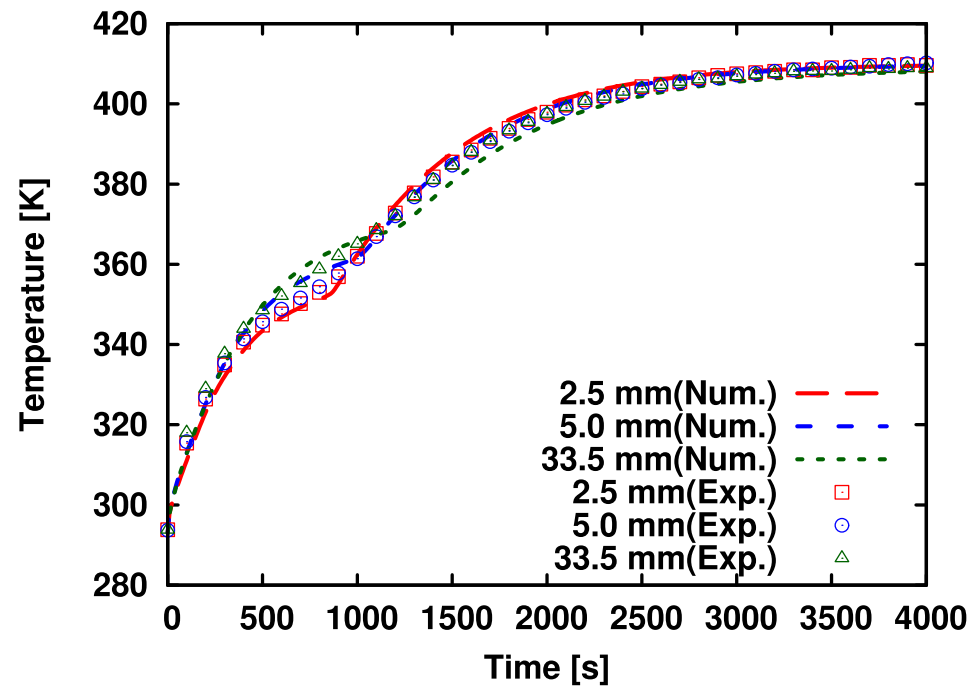

Fig. 12 Comparison of numerical and experimental temperature of the heat source for three pin diameters.

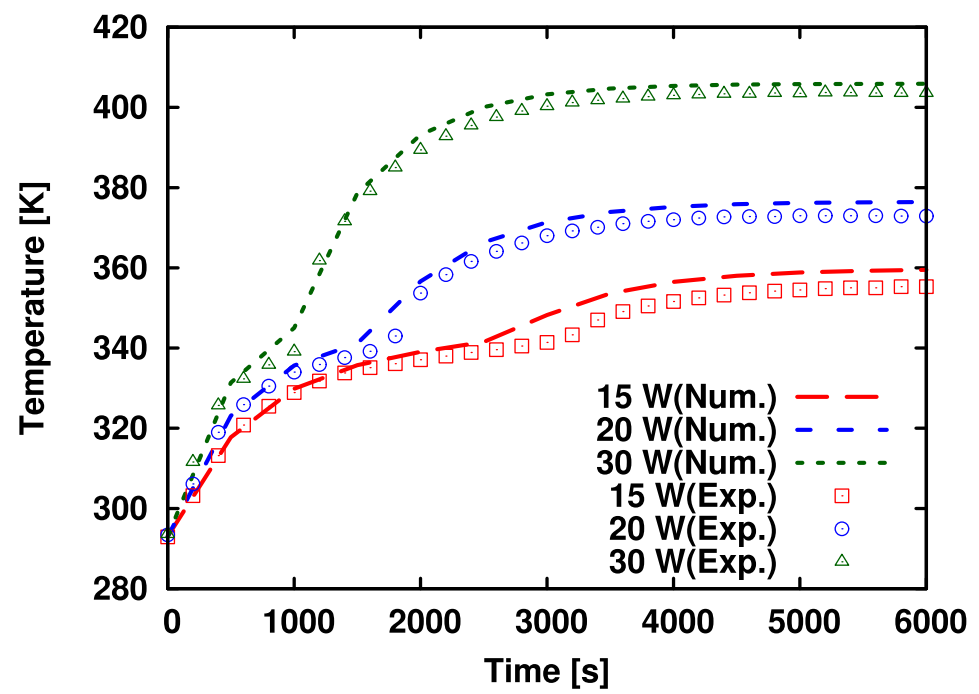

Fig. 13 Comparison of numerical and experimental temperatures of the PCM for three power input levels. 


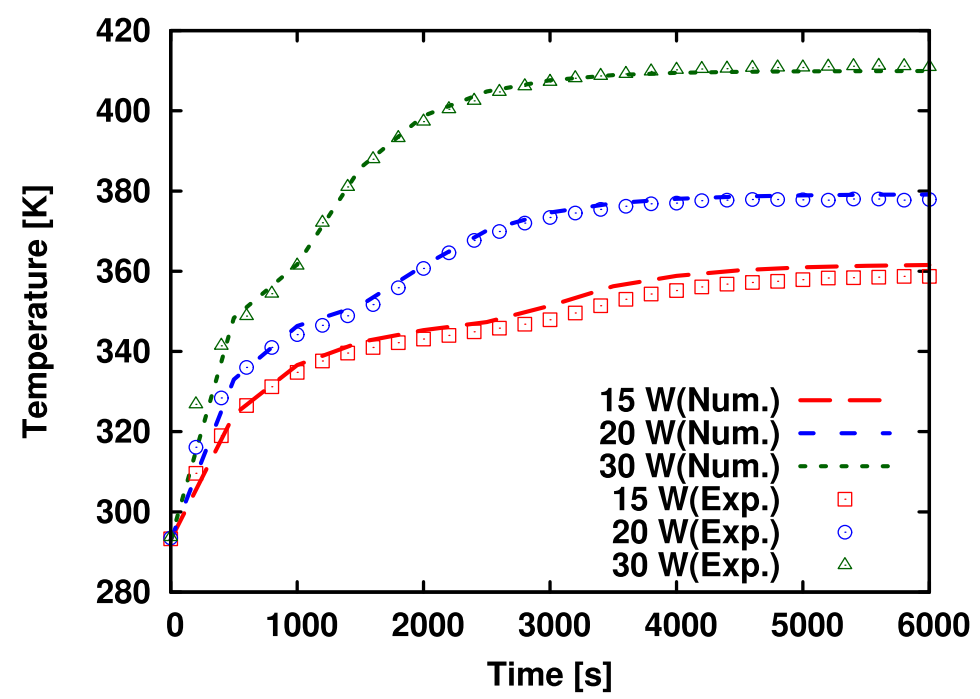

Fig. 14 Comparison of numerical and experimental temperatures of the heat source for three power input levels.

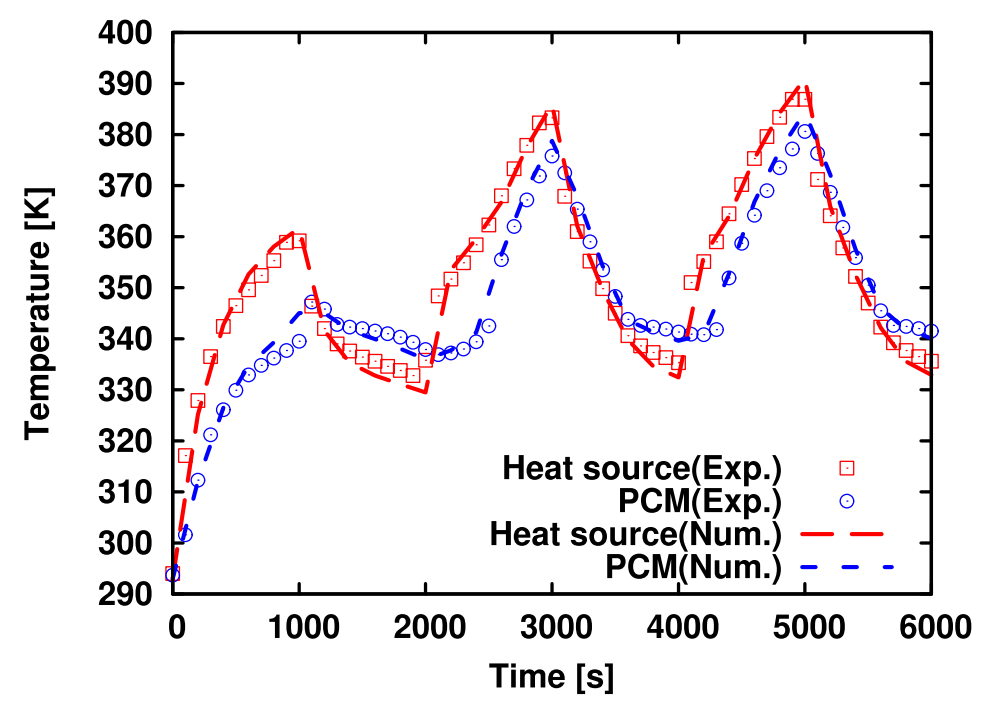

Fig. 15 Comparison of numerical and experimental temperature of the PCM and heat source for varying power operation at $5 \mathrm{~mm}$ fin.

sults. All peaks in the temperature transient are accurately captured by the numerical analysis. Note also that the effect of fusion heat on the moderation of slope on the temperature curve is accurately reproduced on the numerical prediction. These comparisons also mean that the estimations of thermal resistances by natural convection and radiation on the module surface are valid. Discrepancy between the results from the experiment and that from the calculation is less than $6.8 \mathrm{~K}$ on the heat source and $8.2 \mathrm{~K}$ for the PCM at any time. Thermal design only by the thermal network model can be achieved with considering these discrepancies.

\section{Conclusion}

We designed and manufactured a PCM-based module for electronic device cooling. The module has internal pins to enhance heat conduction to the PCM. The study was conducted for different pin designs. The PCM is paraffin wax, a low cost material. In the experimental part of the study, the temperatures were measured at various spots in the PCM and the heat source resistors. We also developed a thermal network model of the module, and proved its capability to predict the temperature transients in the PCM and on the heat source. Both the experimental and analytical results demonstrate the effectiveness of PCM in elongating the 
safe operation time before reaching the steady level dictated by the thermal resistance on the module surface. It is emphasized that the thermal network method is an effective design tool, even where conventional PCMs such as paraffin wax are used. However, it should be noted that several parameters and thermal resistances are determined empirically; they are determined so as to achieve matching of the temperature prediction with the experimental data. Therefore, the thermal network method needs experiments to determine empirical constants and validate the predictions.

\section{References}

( 1 ) Hodes, M., Weinstein, R.D. Pence, S. J., Piccini, J. M. Manzione, L. and Chen, C., Transient Thermal Management of a Handset Using Phase Change Material(PCM), ASME Journal of Electronic Packaging, Vol. 124 (2002), pp. 419-426.

( 2 ) Krishnan, S. and Garimella, S. V., Analysis of a Phase Change Energy Storage System for Pulsed Power Dissipation, IEEE Transaction on Components and Packaging Technology, Vol. 27, No. 1 (2004), pp. 191-199.

( 3 ) Alawadhi, E. M. and Amon, C. H., Thermal Analysis of a PCM Thermal Control Unit for Portable Electronic Devices: Experimental and Numerical Studies, Proc. of ITherm 2002, (2002), pp 466-475.

( 4 ) Pal, D. and Joshi, Y. K., Application of Phase Change Materials to Thermal Control of Electronic Modules: A Computational Study, ASME Journal of Electronic Packaging, Vol. 119 (1997) pp 40-50.

( 5 ) Wirtz, R. A., Zheng, N. and Chandra, D., Thermal Management Using Dry Phase Change Materials, Proc. of IEEE Semiconductor Thermal Measurement and Management Symposium 1999, (1999), pp 74-82.

( 6 ) Zheng, N. and Wirtz, R. A., Methodology for Designing a Hybrid Thermal Energy Storage Heat Sink, Proc. of IMECE2000, (2000), pp 1-8.

( 7 ) Weinstein, R. D., Kopec, T. C., Fleischer, A. S., D’Addio, E. and Bessel, C. A., The Experimental Exploration of Embedding Phase Change Materials with Graphite Nanofibers for the Thermal Management of Electronics, ASME Journal of Heat Transfer, Vol. 130, No. 4 (2008), 042405.

( 8 ) Fleischer, A. S., Chintakrinda, K., Weinstein, R. and Bessel, C. A., Transient Thermal Management Using Phase Change Materials with Embedded Graphite Nanofibers for Systems with High Power Requirements, Proc. of ITherm 2008, (2008), pp 561-566.

( 9 ) Bauer, C. A. and Wirtz, R. A., Thermal Characteristics of a Compact Passive Thermal Energy Storage Devices, Proc. of IMECE2000, (2000), pp 1-7.

(10) Lafdi, K., Mesalhy, O. and Elgafy, A., Merits of Employing Form Encapsulated Phase Change Materials for Pulsed Power Electronics Cooling Application, ASME Journal of Electronic Packaging, Vol. 130, No. 2 (2008), 021004.

(11) Ishizuka, M., Nakagawa, S. and Koizumi, K., Practical Study of Thermal Network Method to Thermal Design of Electronics Cooling Application, Proc. of IMECE2006, (2006), IMECE2006-13105.

(12) Ishizuka, M., Operation Time Control of a High Density Packaging Using a Low Melting Point Alloy, IEEE Transaction on Components and Packaging Technology, Vol. 27, No. 2 (2004), pp 239-243. 